\title{
An Efficient $\Delta$-Circuit approach for Online Short-Circuit Calculation in Large Islanded AC Microgrids
}

This paper was downloaded from TechRxiv (https://www.techrxiv.org).

\section{LICENSE}

CC BY 4.0

SUBMISSION DATE / POSTED DATE

$31-12-2021 / 05-01-2022$

CITATION

Pompodakis, Evangelos (2022): An Efficient $\Delta$-Circuit approach for Online Short-Circuit Calculation in Large Islanded AC Microgrids. TechRxiv. Preprint. https://doi.org/10.36227/techrxiv.17710793.v1

DOI

10.36227/techrxiv.17710793.v1 


\title{
An Efficient $\Delta$-Circuit approach for Online Short- Circuit Calculation in Large Islanded AC Microgrids
}

\author{
Evangelos E. Pompodakis ${ }^{*}$, Alexandros G. Paspatis ${ }^{*}$, Minas Alexiadis ${ }^{\dagger}$, Antonios Tsikalakis*, Yiannis Katsigiannis*, \\ Emmanuel Karapidakis* \\ * Department of Electrical and Computer Engineering, Hellenic Mediterranean University of Crete, Greece. \\ ${ }^{\dagger}$ Department of Electrical and Computer Engineering, Aristotle University of Thessaloniki, Greece
}

\begin{abstract}
In this manuscript, a novel $\Delta$-circuit approach is proposed, which enables the fast calculation of fault currents in large islanded AC microgrids (MGs), supplied by inverter-based distributed generators (IBDGs) with virtual impedance current limiters (VICLs). The concept of virtual impedance for limiting the fault current of IBDGs has gained the interest of research community in the recent years, due to the strong advantages it offers. Moreover, $\Delta$-circuit is an efficient approach, which has been widely applied in the past, for the calculation of shortcircuit currents of transmission and distribution networks. However, the traditional $\Delta$-circuit, in its current form, is not applicable in islanded MGs, due to the particular characteristics of such networks, e.g., the absence of a slack bus. To overcome this issue, a novel $\Delta$-circuit approach is proposed in this paper, with the following distinct features: a) precise simulation of islanded MGs, b) fast computational performance, c) generic applicability in all types of faults e.g., single-line, 2-line or 3-line faults, d) simple extension to other DG current limiting modes, e.g., latched limit strategy etc. The proposed approach is validated through the time-domain software of Matlab Simulink, in a 9-bus and 13-bus islanded MG. The computational performance of the proposed fault analysis method is further tested in a modified islanded version of the IEEE 8500-node network.
\end{abstract}

Index Terms - $\Delta$-circuit, distribution management system, droop control, large islanded microgrids, real-time fault analysis, virtual impedance current limiter.

\section{INTRODUCTION}

$\mathrm{F}$ AULT analysis is one of the basic distribution management system (DMS) applications. In modern DMS systems, the short-circuit calculation (SCC) is carried, in realtime, in multiple possible fault locations, assuming all possible types of faults, in order to check for violations of circuit breaker/fuse breaking capability, the adequacy of the relay sensitivity and the levels of earth fault currents [1]. Moreover, it constitutes the basic tool for several other online applications such as fault location, isolation and supply restoration [2]. As a result, online SCC methods should ideally satisfy two basic features: a) high speed, and b) high accuracy. Online fault analysis is normally executed automatically, either on a cyclic basis or following a request for topology change. A clear explanation about the implementation of SCC in distribution networks is provided in [1, section II].

\section{A. 4 -Circuit Concept for Fast Calculation of Fault Currents}

The $\Delta$-circuit method (also known as "equivalent voltage source method") has been applied in several papers so far, e.g. [1]-[4], to calculate the short circuit currents, fast and accurately. More specifically, according to the superposition theory, a fault state can be decomposed into a pre-fault state and a $\Delta$-circuit state [3]. As the pre-fault state of the system is known from power flow or state estimation, the fault analysis is reduced to the calculation of $\Delta$-circuit.

The $\Delta$-circuit concept assumes that the loads of the network have the same current values before and during the fault. With this assumption, the $\Delta$-circuit is reduced to include only the generator and the faulted buses (namely the buses where the current changes because of the fault), reducing in this way the computation time, significantly. This property is very important in online fault analysis, since only the active buses (namely generator and faulted buses) are involved in the computation process and not the passive ones (load buses).

So far, all the existing $\Delta$-circuit approaches are applicable in grid-connected networks since they all consider a slack bus with a constant voltage, which feeds high short-circuit currents [1]-[4]. An example about the short-circuit calculation using the $\Delta$-circuit approach is presented in Section III, for a small grid-connected network.

However, islanded microgrids (MGs) consist of small inverter-based distributed generators (IBDGs), with current limiting functions. Therefore, in islanded MGs, there is not a slack bus or a large DG (to play the role of a slack bus) to supply high short-circuit currents, constituting traditional $\Delta$ circuit approaches not applicable in such networks.

\section{B. Fault Currents in Islanded AC Microgrids}

IBDGs are assigned with current limiting functions in order to protect their power electronic equipment. Usually, IBDGs are regulated to restrict their fault current up to a small multiple of their nominal current [2], e.g., $I_{\text {fault }} \leq 2 \cdot I_{\text {nom }}$. As a result, fault current of islanded MGs supplied by IBDGs is significantly lower than conventional networks.

There are four basic operational modes of IBDGs, in islanded MGs, as shown in Fig. 1 [5]:

a) Grid-forming $(G F m)$ : It acts as a fixed voltage source, with specified magnitude and frequency.

b) Grid-feeding $(G F e)$ : It acts as a current source. This mode is applied in intermittent DGs that generate fixed active and reactive power, usually based on a MPPT function.

c) Grid-supporting-grid-forming $(G S G F m)$ : It is the most common type in islanded MGs. IBDGs act as voltage sources with variable voltage magnitude and frequency values determined by the droop equations and the output power.

d) Grid-supporting-grid-feeding (GSGFe): It acts as a current source. This type of control is suitable for paralleling multiple 
droop-controlled IBDGs, in a similar sense as GSGFm IBDGs.

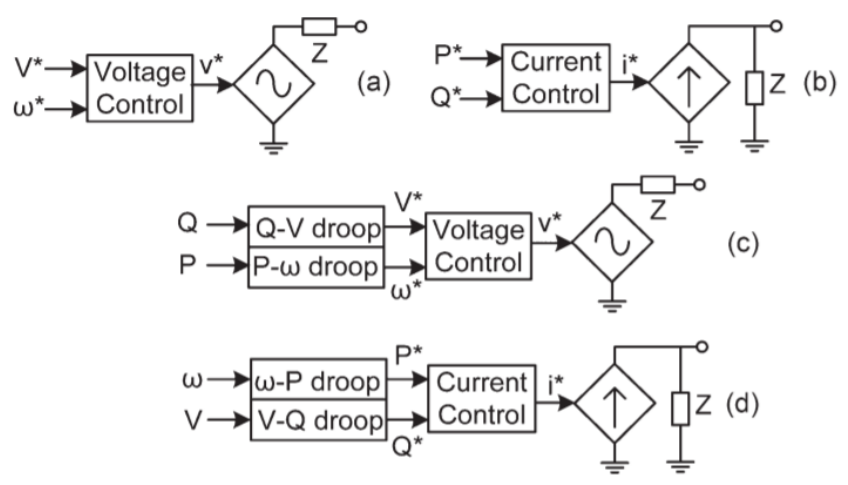

Fig. 1 Four basic types of inverter control. a) Grid-Forming (GFm), b) gridfeeding ( $\mathrm{GFe}), \quad \mathrm{c}$ ) grid-supporting-grid-forming (GSGFm), d) gridsupporting-grid-feeding (GSGFe) [5].

Current-controlled IBDGs, such as GFe and GSGFe, do not require a current limiting mechanism to protect their power electronics since they control directly the current, by their nature. Usually, after a fault occurs, GFe and GSGFe are assigned to inject pre-specified positive- and negativesequence post-fault powers or currents, as explained in [6]-[9].

On the other hand, voltage-controlled IBDGs, such as GFm and GSGFm, require a current-limiting mechanism in order to protect their power electronic devices, because the controlled value is the voltage, and therefore, the current can take large values. The most common approaches for the current limitation of voltage-controlled IBDGs are:

a) instantaneous saturation limit strategy (ISLS) [10]: The inverter output current is instantaneously limited, when its value exceeds a threshold, according to (1) [10]:

$$
I_{L}^{r e f}=\left\{\begin{array}{cl}
I_{\max } & I_{L}^{\text {ref }}>I_{\max } \\
-I_{\max } & I_{L}^{\text {ref }}<-I_{\max } \\
I_{L}^{\text {ref }} & \text { otherwise }
\end{array}\right.
$$

where $I_{\max }$ is the maximum allowable peak current, while $I_{L}^{\text {ref }}$ is the reference inverter current. Although the implementation of this technique is simple, the inverter current is distorted due to crest clipping of the current reference. Moreover, wind-up effects are encountered with this strategy, due to the loss of control of the outer power loop of inverter [12].

b) latched limit strategy (LLS) [10] [11]: In this strategy, the inverter switches from the grid-forming to the grid-feeding mode. More specifically, $I_{L}^{r e f}$ is replaced by a predefined current reference vector, as soon as a fault is detected. Since no crest clipping occurs, the inverter currents are pure sinusoidal. However, as this scheme is largely dependent on the assumption of a stiff voltage at the point of connection, there may be loss of synchronization during weak-grid and fault conditions [12], due to latch-up, especially in islanded MGs where a stiff slack bus is absent.

c) virtual impedance current limiters (VICLs) [5], [12]-[15]: In this method, the current limitation is carried out by reducing the reference voltage of the inverter (and not directly the current), through the introduction of a virtual impedance. As a result, the inverter keeps the voltage-forming characteristics, during the fault, enhancing the stability of MG. Recently, virtual impedance current limiters (VICL) strategy has gained the interest of researchers, due to the high robustness that it offers, especially in weak islanded MGs [5], [12]-[15]. It is pointed out that for stable islanded operation, a MG requires at least one grid-forming inverter to form the voltage of the network, and therefore, during the fault, at least one inverter should necessarily operate in VICL control mode. More details about the VICL are provided in Section III.

\section{Literature Review of Fault Analysis Methods in Islanded MGs.}

Several papers exist in the literature studying the fault response of islanded MGs. However, most of them are restricted only to studying the dynamic short circuit current behavior over the time, and not to propose efficient steadystate short-circuit current solvers, that will facilitate the fault analysis of large islanded MGs. For instance, authors in [16][19] use time-domain software to simulate the dynamic behavior of MGs under fault conditions. However, timedomain software tools are only applicable in small networks, and definitely, not in real time applications of large MGs, due to their time-consuming nature.

The steady-state SCC of MGs has gained the interest of research community over the last years. It is well-recognized that an accurate and computationally efficient SCC method is necessary in order to develop effective protection systems for grid-connected and islanded MGs. Nevertheless, MGs present a completely different short-circuit current profile in gridconnected and islanded modes (due to the absence of a slack bus in islanded mode). As a result, different algorithms need to be developed for the two operational modes of MGs.

The development of steady-state SCC algorithms for gridconnected MGs has been efficiently addressed so far. A steady-state SCC method was proposed in [20], using graph theory and matrix decomposition, to calculate SCC in gridconnected MGs. However, this method is not applicable in islanded MGs. Moreover, the method involves into the calculation all the buses of the network, even the load buses, and thus, the computation time is increased in large networks. The issue of computation time in grid-connected MGs is addressed in [2], in which the authors involve into the SCC only the active DG and faulted buses. Nevertheless, the method of [2], although computationally efficient, it is not accurate in islanded networks, as proved in [21, section 6].

In [22] and [23], two SCC methods were proposed for islanded MGs operating in master-slave control. However, the methods are not applicable in droop-controlled MGs. Moreover, since they involve into the SCC all the buses of the MG, it is questionable, what is the computation time of these methods, when applied in large MGs.

Finally, in [24], a SCC method was proposed, which can be applied in both grid-connected and droop-controlled islanded MGs. Nonetheless, it is a very time-consuming method with complex implementation, when applied in large networks, as it requires the solution of a non-linear system with $2 \cdot \mathrm{N}$ equations, where $N$ is the total number of network buses.

\section{Contribution of this Paper}


This paper overcomes the drawbacks of the aforementioned methods, by proposing a SCC algorithm with two distinct features:

$\checkmark \quad$ It can be accurately applied in droop-controlled islanded MGs, for all types of faults. Simulation results in section $\mathrm{V}$, indicate that the results of the proposed SCC approach are very close to those of Simulink. It is pointed out that in this paper, we investigated only IBDGs with VICLs, due to space limitation. However, the proposed method can be also applied in IBDGs with ISLS, LLS as well as in type III wind generators, using the modelling approach of [2].

$\checkmark \quad$ It presents high computational performance. Simulation results in section VI, demonstrate that the proposed SCC method can calculate the fault currents of the IEEE 8500node network in around $8 \mathrm{~ms}$, making the method a powerful SCC solver for real-time DMS applications.

\section{E. Structure of the Paper}

The rest of the paper is structured, as follows: Section II describes the concept of droop-control with VICLs, while section III explains the traditional $\Delta$-circuit approach for the calculation of short-circuit currents. The proposed $\Delta$-circuit approach is described in section IV. The method is validated in section $\mathrm{V}$, while its computation performance is tested in section VI. Finally, section VII concludes the paper.

\section{DroOP-CONTROL WITH VIRTUAL IMPEDANCE CURRENT LIMITERS}

In normal operation of islanded MGs, IBDGs usually operate in droop-control for sharing the active and reactive power of the network. More specifically, the frequency and voltage of IBDGs are determined by the positive sequence powers, as follows [25] [26]:

$$
\begin{gathered}
f=f_{\text {ref }(i)}-K_{P(i)} \cdot P_{G i} \\
V_{p o s(i)}=V_{\text {ref }(i)}-K_{Q(i)} \cdot Q_{G i}
\end{gathered}
$$

where $f, f_{\text {ref }(i)}, K_{P(i)}, P_{G i}, V_{\text {pos }(i)}, V_{\text {ref(i) }}, K_{Q(i)}$ and $Q_{G i}$ are the network frequency, reference frequency, frequency droop gain, positive-sequence active power output, positivesequence voltage magnitude, reference voltage, voltage droop gain, and positive sequence reactive power output of DG at bus $i$, respectively.

Droop equation (2) ensures the equal sharing of active power between the IBDGs since they all sense the same frequency. On the other hand, with droop equation (3), the equal reactive power sharing is not ensured between the DGs, because they sense a different voltage $V_{\text {pos }(i)}$, depending on their location in the MG.

To overcome this issue, the virtual impedance control concept is widely used [26], according to which, the positivesequence output voltage of IBDG $i\left(\overrightarrow{V_{G p o s(l)}}\right)$ is determined by (4).

$$
\overrightarrow{V_{G p o s(l)}}=\overrightarrow{V_{\text {virt_pos }(l)}}-\overrightarrow{I_{G \_p o s}(l)} \cdot \overrightarrow{Z_{\text {DGi_virt } 1}}
$$

In (4), $\overrightarrow{V_{\text {virt_pos(l) }}}$ is the internal virtual positive-sequence voltage formed by the droop equations (2)-(3), $\overrightarrow{I_{G_{-}} p o s(l)}$ is the positive-sequence output current of IBDG $i, \overrightarrow{Z_{D G L_{-} \text {virt } 1}}$ is the positive-sequence virtual impedance of IBDG $i$.
Looking at (4), the magnitude of the output voltage of IBDG $i$ depends highly on the magnitude of $\overrightarrow{Z_{D G L} \text { virt } 1}$. In normal operation, $\overrightarrow{Z_{D G l_{-} \text {virt } 1}}$ has a low value so that the output voltage of DG is kept in a high level avoiding undervoltages. On the other hand, during a fault, $\overrightarrow{Z_{D G l_{-} \text {vort } 1}}$ is suitably increased in order to reduce the output voltage of IBDG, and hence, to limit the fault current generated by the IBDG. VICLs have been recently applied in [5], [12]-[15] with very promising results. The strong advantage of VICLs against other current-limiting approaches is that IBDGs keep their grid-forming nature, during the fault, which is necessary for the stability of islanded MGs, in the absence of a stiff slack bus.

III. Calculation of Steady-State Fault Currents WITH THE $\triangle$-CIRCUIT APPROACH IN GRID-CONNECTED NETWORKS

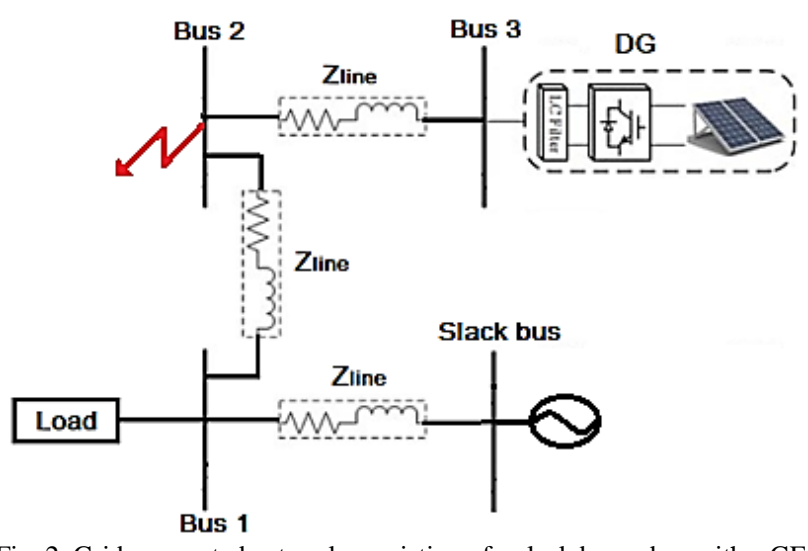

Fig. 2. Grid-connected network consisting of a slack bus, a bus with a GFe IBDG, a load bus and a faulted bus.

In this section, the concept of $\Delta$-circuit for the calculation of fault currents of grid-connected networks is explained, using the simple network of Fig. 2. It consists of a slack bus, which keeps its voltage constant despite the fault currents, a load bus (bus 1), a DG bus (bus 3 ) and the faulted bus (bus 2).

In the online fault analysis of DMS, the power flow is initially solved for the pre-fault loading condition. Subsequently, the short-circuit current is calculated with the superposition theory, using the pre-fault voltages and currents (e.g., $\overrightarrow{V_{1}^{p r e}}, \overrightarrow{I_{1}^{p r e}}$ ) obtained from the power flow. More specifically, the post-fault three-phase voltages of each bus of the network (e.g., $\overrightarrow{V_{1}^{\text {post }}}, \overrightarrow{V_{2}^{\text {post }}}, \overrightarrow{V_{3}^{\text {post }}}$ ) can be calculated from the equation system (5)-(9), as a function of the current variation of each bus due to the fault (e.g., $\overrightarrow{I_{1}^{p o s t}}-\overrightarrow{I_{1}^{p r e}}$ ) and the pre-fault voltages (e.g., $\overrightarrow{V_{1}^{p r e}}, \overrightarrow{V_{2}^{p r e}}, \overrightarrow{V_{3}^{p r e}}$ ).

$$
\begin{aligned}
& \overrightarrow{Z_{11}} \cdot\left(\overrightarrow{I_{1}^{p o s t}}-\overrightarrow{I_{1}^{p r e}}\right)+\overrightarrow{Z_{12}} \cdot\left(\overrightarrow{I_{2}^{p o s t}}-\overrightarrow{I_{2}^{p r e}}\right)+\overrightarrow{Z_{13}} \cdot\left(\overrightarrow{I_{3}^{p o s t}}-\overrightarrow{I_{3}^{p r e}}\right)= \\
& =\overrightarrow{V_{1}^{p o s t}}-\overrightarrow{V_{1}^{p r e}} \\
& \left.\overrightarrow{Z_{21}} \cdot \overrightarrow{\left(I_{1}^{\text {post }}\right.}-\overrightarrow{I_{1}^{p r e}}\right)+\overrightarrow{Z_{22}} \cdot\left(\overrightarrow{I_{2}^{\text {post }}}-\overrightarrow{I_{2}^{\text {pre }}}\right)+\overrightarrow{Z_{23}} \cdot\left(\overrightarrow{I_{3}^{\text {post }}}-\overrightarrow{I_{3}^{p r e}}\right)= \\
& =\overrightarrow{V_{2}^{\text {post }}}-\overrightarrow{V_{2}^{\text {pre }}} \\
& \left.\overrightarrow{Z_{31}} \cdot \overrightarrow{\left(I_{1}^{p o s t}\right.}-\overrightarrow{I_{1}^{p r e}}\right)+\overrightarrow{Z_{32}} \cdot\left(\overrightarrow{I_{2}^{p o s t}}-\overrightarrow{I_{2}^{p r e}}\right)+\overrightarrow{Z_{33}} \cdot\left(\overrightarrow{I_{3}^{p o s t}}-\overrightarrow{I_{3}^{p r e}}\right)= \\
& =\overrightarrow{V_{3}^{p o s t}}-\overrightarrow{V_{3}^{p r e}}
\end{aligned}
$$




$$
\begin{gathered}
\overrightarrow{I_{3}^{\text {post }}}=f\left(\overrightarrow{V_{3}^{\text {post }}}\right) \\
C_{I 3 \varphi} \cdot \overrightarrow{I_{2}^{\text {post }}}+C_{V 3 \varphi} \cdot \overrightarrow{V_{2}^{\text {post }}}=0
\end{gathered}
$$

An explanation of the terms of the equation system above, is given below:

$\overrightarrow{Z_{u l}}$ : It is the self-impedance of bus $i$. It is a submatrix of the $Z_{B U S}$ matrix of the network.

$\overrightarrow{Z_{\imath \jmath}}$ : It is the mutual-impedance between buses $i$ and $j$. It is a submatrix of the $\boldsymbol{Z}_{\boldsymbol{B} \boldsymbol{B} \boldsymbol{S}}$ matrix of the network.

$\overrightarrow{I_{l}^{\text {post }}}=\left[\begin{array}{lll}\overrightarrow{I_{l A}^{\text {post }}} & \overrightarrow{I_{l B}^{\text {post }}} & \overrightarrow{I_{l C}^{\text {post }}}\end{array}\right]^{T}:$ It is the vector that includes the post-fault three-phase currents of bus $l$.

$\overrightarrow{I_{l}^{p r e}}=\left[\begin{array}{lll}\overrightarrow{I_{l A}^{p r e}} & \overrightarrow{I_{l B}^{p r e}} & \overrightarrow{I_{l C}^{p r e}}\end{array}\right]^{T}:$ It is the vector that includes the prefault three-phase currents of bus $l$. It is known from the power flow solution.

$\overrightarrow{V_{l}^{\text {post }}}=\left[\begin{array}{lll}\overrightarrow{V_{l A}^{\text {post }}} & \overrightarrow{V_{l B}^{\text {post }}} & \overrightarrow{V_{l C}^{\text {post }}}\end{array}\right]^{\boldsymbol{T}}:$ It is the vector that includes the post-fault three-phase voltages of bus $l$.

$\overrightarrow{V_{l}^{p r e}}=\left[\begin{array}{lll}\overrightarrow{V_{l A}^{p r e}} & \overrightarrow{V_{l B}^{p r e}} & \overrightarrow{V_{l C}^{p r e}}\end{array}\right]^{T}:$ It is the vector that includes the pre-fault three-phase voltages of bus $l$. It is known from the power flow solution.

$f$ function: It is a function that relates the post-fault current and voltage of DG, depending on the post-fault control mode of DG.

$C_{I 3 \varphi}$ : It is given in equations (31)-(41) of [1], for several types of faults.

$C_{V 3 \varphi}:$ It is given in equations (31)-(41) of [1], for several types of faults.

Equation system (5)-(9) relates the pre-fault with the postfault state of the network. Nevertheless, by assuming that the post-fault current of load buses is equal to the pre-fault one, the load buses are excluded from the calculations and the $\Delta$ circuit equations are significantly simplified, especially in large networks, where the load buses are by far the dominant type of buses. Under this assumption, the $\Delta$-circuit equations of the network of Fig. 2 become:

$$
\begin{gathered}
\left.\overrightarrow{Z_{22}} \cdot \overrightarrow{\left(I_{2}^{\text {post }}\right.}-\overrightarrow{I_{2}^{\text {pre }}}\right)+\overrightarrow{Z_{23}} \cdot\left(\overrightarrow{I_{3}^{\text {post }}}-\overrightarrow{I_{3}^{\text {pre }}}\right)=\overrightarrow{V_{2}^{p o s t}}-\overrightarrow{V_{2}^{p r e}} \\
\left.\overrightarrow{Z_{32}} \cdot \overrightarrow{\left(I_{2}^{\text {post }}\right.}-\overrightarrow{I_{2}^{\text {pre }}}\right)+\overrightarrow{Z_{33}} \cdot\left(\overrightarrow{I_{3}^{\text {post }}}-\overrightarrow{I_{3}^{p r e}}\right)=\overrightarrow{V_{3}^{p o s t}}-\overrightarrow{V_{3}^{p r e}} \\
\overrightarrow{I_{3}^{\text {post }}}=f\left(\overrightarrow{V_{3}^{\text {post }}}\right) \\
C_{I 3 \varphi} \cdot \overrightarrow{I_{2}^{\text {post }}}+C_{V 3 \varphi} \cdot \overrightarrow{V_{2}^{\text {post }}}=0
\end{gathered}
$$

Solving equation system (10)-(13) we can obtain the fault current of the faulted bus and DG buses. Then, knowing the fault current of the active buses, we can easily calculate the voltages of all buses (active and passive) of the network.

The equation system (10)-(13) premises the existence of a slack bus with a constant voltage source. As a result, it is not applicable in islanded MGs, in which a stiff slack bus is absent. In the next section, we overcome the aforementioned restriction, by proposing a $\Delta$-circuit model, which is applicable in islanded MGs (without a slack bus) supplied by IBDGs with VICLs.

\section{PROPOSED $\Delta$-CIRCUIT APPROACH FOR EFFICIENT CALCULATION OF THE FAULT CURRENTS IN ISLANDED MICROGRIDS WITH VICLS}

This section is divided into two sub-sections: a) In order to explain the proposed method, it is deemed necessary, in the first sub-section, to quote the steady-state mathematical model of droop-controlled IBDGs with VICLs. b) The proposed $\Delta$ circuit model is explained in the second sub-section by using, as an example, the islanded MG of Fig. 3.

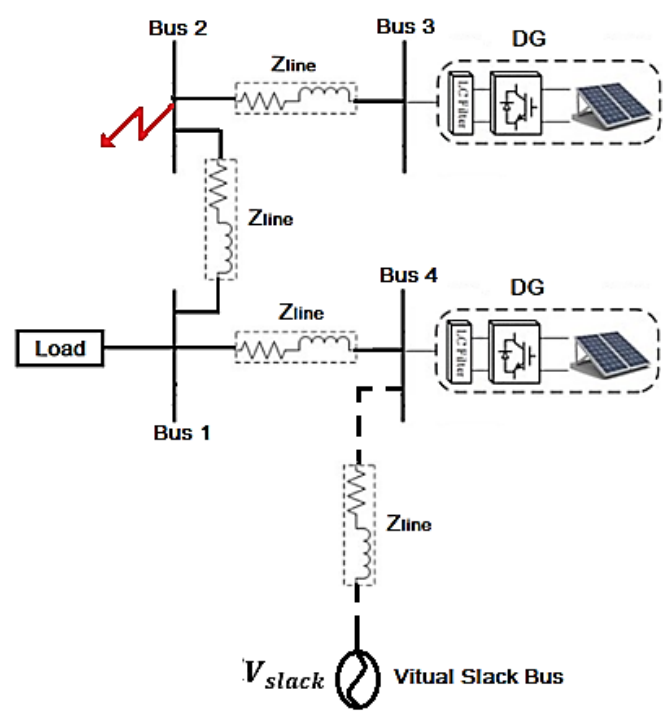

Fig. 3. Islanded MG consisting of a virtual slack bus [26], two IBDGs with VICLs, a load bus and a faulted bus.

A)

\section{Modelling of IBDGs with VICLs}

The sequence components of the IBDG of say bus 3 are depicted in Fig. 4, while their equations are given in (14)-(16). IBDG of bus 4 has the same modeling.

$$
\begin{aligned}
& \overrightarrow{V_{3 p o s}^{\text {post }}}=\overrightarrow{V_{\text {virt_pos }(3)}}-\overrightarrow{I_{3 p o s}^{\text {post }}} \cdot \overrightarrow{Z_{D G 3 \_v i r t 1}} \\
& \overrightarrow{V_{3 n e g}^{\text {post }}}=-\overrightarrow{I_{3 \text { neg }}^{\text {post }}} \cdot \overrightarrow{Z_{D G 3 \_v i r t 2}} \\
& \overrightarrow{V_{3 z e r o}^{\text {post }}}=-\overrightarrow{I_{3 z e r o}^{\text {post }}} \cdot \overrightarrow{Z_{D G 3 \_v i r t 0}}
\end{aligned}
$$

As shown, the positive-sequence component is modeled by a virtual impedance $\left(\overrightarrow{Z_{D G 3_{-} \text {vvrt } 1}}\right)$ and a voltage source, the vector of which is determined by the droop equations (2)-(3). The negative- and zero-sequence components are modeled with two virtual impedances $\left(\overrightarrow{Z_{D G 3} \text { vort2 }}, \overrightarrow{Z_{D G 3 \_v i r t 0}}\right)$. It is noted that the three components are modelled with three separate impedances for the sake of generality.

Equation system (14)-(16) is written in a compact form, as shown in (17): 


$$
\begin{aligned}
& \overrightarrow{\boldsymbol{A}} \cdot\left[\begin{array}{l}
\overrightarrow{V_{3 A}^{\text {post }}} \\
\frac{V_{3 B}^{\text {post }}}{V_{3 C}^{\text {post }}}
\end{array}\right]=\left[\begin{array}{c}
\frac{0}{V_{\text {virt_pos(3) }}} \\
0
\end{array}\right]- \\
& {\left[\begin{array}{ccc}
Z_{D G 3_{-} v i r t 0} & 0 & 0 \\
0 & \underset{Z_{D G 3 \_v v r t 1}}{\longrightarrow} & 0 \\
0 & 0 & \overrightarrow{Z_{D G 3 \_v v r t 2}}
\end{array}\right] \cdot \overrightarrow{\boldsymbol{A}} \cdot\left[\begin{array}{l}
\overrightarrow{I_{3 A}^{\text {post }}} \\
\overrightarrow{I_{3 B}^{\text {post }}} \\
\overrightarrow{I_{3 C}^{\text {post }}}
\end{array}\right]}
\end{aligned}
$$

where the matrix $\vec{A}$ is given below.

$$
\overrightarrow{\boldsymbol{A}}=\frac{1}{3} \cdot\left[\begin{array}{ccc}
1 & 1 & 1 \\
1 & a & a^{2} \\
0 & a^{2} & a
\end{array}\right]
$$

By multiplying both sides of (17) with $\boldsymbol{A}^{-1}$, (18) is finally obtained, which describes the three-phase post-fault voltages of IBDG of bus 3, as a function of three-phase post-fault currents.

$$
\begin{aligned}
& {\left[\begin{array}{l}
\overrightarrow{V_{3 A}^{\text {post }}} \\
\overrightarrow{V_{3 B}^{\text {post }}} \\
\overrightarrow{V_{3 C}^{\text {post }}}
\end{array}\right]=\overrightarrow{\boldsymbol{A}}^{-1} \cdot\left[\begin{array}{c}
0 \\
V_{\text {virt }_{\text {pos(3) }}} \\
0
\end{array}\right]-\overrightarrow{\boldsymbol{A}}^{-1}}
\end{aligned}
$$

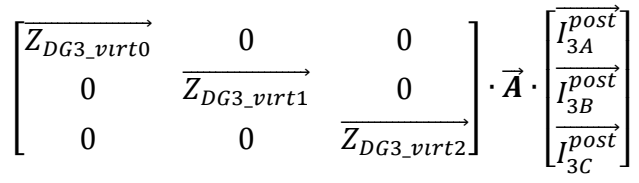

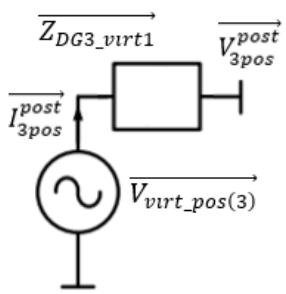

a)

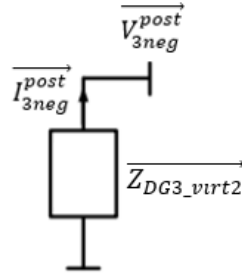

b)

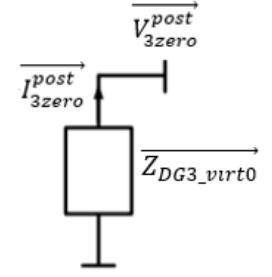

c)
Fig. 4. a) Positive-sequence, b) negative-sequence, c) zero-sequence component of the IBDG of bus 3 .

\section{B) Equations of the proposed 4 -circuit model}

In order to solve the three-phase power flow of islanded MGs, the concept of virtual slack bus is proposed in [26]. More specifically, in the absence of a real slack bus, a virtualslack bus is connected to a random bus of the network to enable the solution of power flow. The voltage of the virtual slack bus is suitably updated in every power flow iteration in order to nullify the current flowing through it. In this way, the addition of the virtual slack bus enables the solution of power flow, without affecting the power flow results [26].

In grid-connected networks, the slack bus voltage is constant, and therefore, it is not considered in the $\Delta$-circuit equations, as shown in (10)-(13). On the contrary, in islanded MGs, the virtual slack bus voltage is varied during the short circuit (in order to obtain equal voltage with its adjacent bus). Hence, the voltage variation of virtual slack bus should be suitably considered in $\Delta$-circuit equations. The $\Delta$-circuit equations of islanded MG of Fig. 3 are the equations (19)-(25) below.

$$
\begin{aligned}
& \overrightarrow{Z_{22}} \cdot\left(\overrightarrow{I_{2}^{p o s t}}-\overrightarrow{I_{2}^{p r e}}\right)+\overrightarrow{Z_{23}} \cdot\left(\overrightarrow{I_{3}^{p o s t}}-\overrightarrow{I_{3}^{p r e}}\right)+\overrightarrow{Z_{24}} \cdot\left(\overrightarrow{I_{4}^{p o s t}}-\overrightarrow{I_{4}^{p r e}}\right)+ \\
& \overrightarrow{d V_{\text {slack }}}=\overrightarrow{V_{2}^{p o s t}}-\overrightarrow{V_{2}^{p r e}} \\
& \overrightarrow{Z_{32}} \cdot\left(\overrightarrow{I_{2}^{p o s t}}-\overrightarrow{I_{2}^{p r e}}\right)+\overrightarrow{Z_{33}} \cdot\left(\overrightarrow{I_{3}^{p o s t}}-\overrightarrow{I_{3}^{p r e}}\right)+\overrightarrow{Z_{34}} \cdot\left(\overrightarrow{I_{4}^{p o s t}}-\overrightarrow{I_{4}^{p r e}}\right)+ \\
& \overrightarrow{d V_{\text {slack }}}=\overrightarrow{V_{3}^{\text {post }}}-\overrightarrow{V_{3}^{\text {pre }}} \\
& \overrightarrow{Z_{42}} \cdot\left(\overrightarrow{I_{2}^{p o s t}}-\overrightarrow{I_{2}^{p r e}}\right)+\overrightarrow{Z_{43}} \cdot\left(\overrightarrow{I_{3}^{p o s t}}-\overrightarrow{I_{3}^{p r e}}\right)+\overrightarrow{Z_{44}} \cdot\left(\overrightarrow{I_{4}^{p o s t}}-\overrightarrow{I_{4}^{p r e}}\right)+ \\
& \overrightarrow{d V_{\text {slack }}}=\overrightarrow{V_{4}^{p o s t}}-\overrightarrow{V_{4}^{p r e}} \\
& C_{I 3 \varphi} \cdot \overrightarrow{I_{2}^{p o s t}}+C_{V 3 \varphi} \cdot \overrightarrow{V_{2}^{p o s t}}=0 \\
& \left(\overrightarrow{I_{2}^{p o s t}}-\overrightarrow{I_{2}^{p r e}}\right)+\left(\overrightarrow{I_{3}^{p o s t}}-\overrightarrow{I_{3}^{p r e}}\right)+\left(\overrightarrow{I_{4}^{p o s t}}-\overrightarrow{I_{4}^{p r e}}\right)=0 \\
& \overrightarrow{V_{3}^{p o s t}}=\vec{A}^{-1} \cdot \overrightarrow{E_{3}}-\vec{A}^{-1} \cdot \overrightarrow{Z_{D G 3_{-} v t r t}} \cdot \vec{A} \cdot \overrightarrow{I_{3}^{\text {post }}} \\
& \overrightarrow{V_{4}^{p o s t}}=\vec{A}^{-1} \cdot \overrightarrow{E_{4}}-\vec{A}^{-1} \cdot \overrightarrow{Z_{D G 4 \_v i r t}} \cdot \vec{A} \cdot \overrightarrow{I_{4}^{p o s t}}
\end{aligned}
$$

As shown, there is an additional variable $\boldsymbol{d} \boldsymbol{V}_{\text {slack }}=$ $\left[\begin{array}{lll}\boldsymbol{d} \boldsymbol{V}_{\boldsymbol{A}_{-} \text {slack }} & \boldsymbol{d} \boldsymbol{V}_{\boldsymbol{B}_{-} \text {slack }} & \boldsymbol{d} \boldsymbol{V}_{\boldsymbol{C}_{-} \text {slack }}\end{array}\right]^{\boldsymbol{T}}$ in the equations that represents the voltage variation of the virtual slack bus. $d V_{r_{\text {_s slack }}}$ denotes the variation of the voltage of phase $r=\{\mathrm{A}, \mathrm{B}$, C) of the virtual slack bus.

Moreover, in islanded MGs, the current flowing through the phases of virtual slack bus should be always zero because it is not a real bus, but an imaginary one. In order to satisfy this condition, the summation of the variations between pre- and post-fault currents of all buses should be zero. This condition is expressed by (23). Finally, the relation between post-fault currents and voltages for the two IBDGs is expressed in (24) and (25), according to (18).

Equation system (19)-(25) is a linear system of 7 complex equations with 7 complex unknown vectors, namely $\overrightarrow{\boldsymbol{I}_{2}^{\text {post }}}$, $\overrightarrow{I_{3}^{\text {post }}}, \overrightarrow{I_{4}^{\text {post }}}, \overrightarrow{d V_{\text {slack }}}, \overrightarrow{V_{2}^{\text {post }}}, \overrightarrow{V_{3}^{\text {post }}}, \overrightarrow{V_{4}^{\text {post }}}$. As it can be seen, it considers only the currents and voltages of the DG and faulted buses, and not the load buses, which are by far the most numerous. In this way, the computation complexity of shortcircuit analysis is significantly reduced.

A raised question in the equation system (19)-(25), is how to calculate the $\overrightarrow{\boldsymbol{E}_{\mathbf{3}}}$ and $\overrightarrow{\boldsymbol{E}_{\mathbf{4}}}$ vectors in the proposed model. $\overrightarrow{\boldsymbol{E}_{\mathbf{3}}}$ and $\overrightarrow{\boldsymbol{E}_{\mathbf{4}}}$ include the positive-sequence virtual voltages (please see $\overrightarrow{V_{\text {virt_pos(3) }}}$ in eq. (18)), which are formed, depending on the control mode of IBDG during the fault. For example, Zarei et. al. in [15] keep the virtual voltage sources equal to the prefault values, during the fault. On the other hand, Paquette et. al. in [5] and Lu et. al. in [13] preserve the droop control during the fault.

The equation system (19)-(25) is generic and can be applied in all post-fault control modes of IBDGs. In this paper, we consider that IBDG preserves the droop control during the fault. Therefore, the vectors $\overrightarrow{\boldsymbol{E}_{\mathbf{3}}}$ and $\overrightarrow{\boldsymbol{E}_{\mathbf{4}}}$ are calculated from the droop equations (2)-(3). More specifically, the magnitude and angle of $\overrightarrow{V_{\text {virt_pos(3) }}}$ and $\overrightarrow{V_{\text {virt_pos(4) }}}$ are calculated from the reactive and active power of DGs, respectively. Inevitably, this introduces a non-linearity in the equation system, which needs to be iteratively solved, with numerical analysis. 
Nevertheless, due to the low number of equations and unknown variables, the computation time remains extremely low.

\section{VALIDATION RESULTS}

The proposed fault analysis solver is validated against the dynamic simulation results of Simulink. Simulink is a timedomain simulation tool, which is well-recognized by the research community due to its high accuracy. For the validation we used a 9-bus and a 13-bus islanded network.

\section{A) 9-Bus network}

The investigated 9-bus islanded network is depicted in Fig. 5 , at the end of the paper. It consists of 3 droop-controlled IBDGs with virtual-impedances. Before the fault, the virtual impedances are low, and their role is to equally share the reactive power between the IBDGs [26]. After the fault, the virtual impedance is highly increased, in order to reduce the IBDG current and protect the power electronic semiconductors. The three-phase loads of the network are assumed balanced before the fault.

Data about the network, the droop equations and virtual impedance of DGs are provided in Table I. Different types of faults e.g., single-line to ground (SLG), line to line (LL), 2line to ground (2LG), 3-line to ground (3LG) are assumed to occur in bus 8 . In all cases, the fault impedance is $0.05 \Omega$. The results of the proposed method and Simulink are quoted in Tables II and III, at the end of the paper, for two cases of postfault virtual impedances: $\left(Z_{D G i_{-} \text {virt1 }}, Z_{D G i_{-} \text {virt2 }}, Z_{D G i_{-} \text {virto }}\right)=$ $(20 \mathrm{j}, 20 \mathrm{j}, 20 \mathrm{j}) \Omega$ and $\left(Z_{D G i \_v i r t 1}, Z_{D G i \_v i r t 2}, Z_{D G i \_v i r t 0}\right)=(50 \mathrm{j}, 50 \mathrm{j}$, $50 \mathrm{j}) \Omega$, respectively. As shown, the steady-state results of the proposed approach are very close to those of Simulink, for both cases, confirming the high accuracy of the proposed method. It is also noted that, as expected, the fault currents of DGs are significantly reduced with the rise of virtual impedance.

TABLE I

DATA OF THE 9-BUS NETWORK

\begin{tabular}{|c|c|}
\hline Line Lengths & $5 \mathrm{~km}$ \\
\hline Resistance of the lines & $0.3 \Omega / \mathrm{km}$ \\
\hline Reactance of the lines & $0.3 \Omega / \mathrm{km}$ \\
\hline Short circuit resistance & $0.05 \Omega$ \\
\hline Active power load of each phase & $0.25 \mathrm{MW}$ \\
\hline Power factor of each phase & 0.97 inductive \\
\hline Phase-to-phase nominal voltage & $20 \mathrm{kV}$ \\
\hline $\begin{array}{l}\text { Virtual impedance of } \mathrm{DGs} \text { before fault } \\
\left(Z_{D G i_{2} \text { virt } 1}, Z_{D G i \_ \text {virt } 2}, Z_{D G i_{\text {_virt } 0}}\right)\end{array}$ & $(2 \mathrm{j}, 2 \mathrm{j}, 2 \mathrm{j}) \Omega$ \\
\hline Virtual impedance of DGs during the fault & Case $1:(20 \mathrm{j}, 20 \mathrm{j}, 20 \mathrm{j}) \Omega$ \\
\hline$\left(Z_{D G i \_ \text {virt } 1}, Z_{D G i \text { virt } 2}, Z_{D G i \text { virt } 0}\right)$ & Case $2:(50 \mathrm{j}, 50 \mathrm{j}, 50 \mathrm{j}) \Omega$ \\
\hline $\begin{array}{c}\text { Reference voltage of droop equation } \\
\left(V_{r e f(i)}\right)\end{array}$ & $11547 \mathrm{~V}$ \\
\hline $\begin{array}{l}\text { Reference frequency of droop equation } \\
\qquad\left(f_{\text {ref }(i)}\right)\end{array}$ & $50 \mathrm{~Hz}$ \\
\hline $\begin{array}{l}\text { Reactive power droop gain of DG } \\
\left(K_{Q(i)} \text { for } i=\{1,2,3\}\right)\end{array}$ & $10^{-4} \mathrm{~V} / \mathrm{Var}$ \\
\hline $\begin{array}{l}\text { Active power droop gain of DG } \\
\left(K_{P(i)} \text { for } i=\{1,2,3\}\right)\end{array}$ & $10^{-7}(\mathrm{~Hz} / \mathrm{W})$ \\
\hline
\end{tabular}

\section{B) 13-Bus network}

The investigated 13-bus islanded network is depicted in Fig. 6 , below. It consists of 4 droop-controlled IBDGs with virtual impedances. Before the fault, the virtual impedances are low, while after the fault, they are increased, in a similar sense, as in 9-bus MG. The three-phase loads of the network are assumed balanced before the fault.

Data about the network, the droop equation and virtual impedance of DGs are provided in Table IV. Different types of faults e.g., SLG, LL, 2LG, 3LG are assumed to occur in bus 680. In all cases, the fault impedance is $0.05 \Omega$. The results of the proposed fault analysis method and Simulink are quoted in Tables V and VI, at the end of the paper, for two cases of postfault impedances: $\left(Z_{D G i \_ \text {virt } 1}, Z_{D G i \text { virt } 2}, Z_{D G i \_ \text {virt } 0}\right)=(20 \mathrm{j}$, $20 \mathrm{j}, 20 \mathrm{j}) \Omega$ and $\left(Z_{D G i \_ \text {virt } 1}, Z_{D G i \_ \text {virt } 2}, Z_{D G i \_ \text {virt } 0}\right)=(70 \mathrm{j}, 70 \mathrm{j}, 70 \mathrm{j}) \Omega$, respectively. It is pointed out that the pre-fault magnitudes of the currents of DG1, DG2, DG3 and DG4 are 44.9A, 44.9A, 46.18 and 45.4 A, respectively, and they are all balanced. As shown, the steady-state results of the proposed approach are very close to those of Simulink, confirming again the high accuracy of the proposed approach. It is also confirmed that a large virtual impedance reduces significantly the fault current.

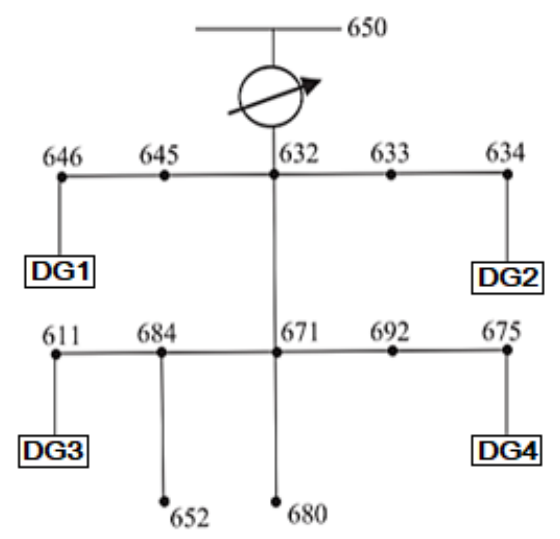

Fig. 6. Modified IEEE 13-Bus test feeder

TABLE IV

DATA OF THE 13-BUS NETWORK

\begin{tabular}{|c|c|}
\hline Line Lengths & $2 \mathrm{~km}$ \\
\hline Resistance of the lines & $0.3 \Omega / \mathrm{km}$ \\
\hline Reactance of the lines & $0.3 \Omega / \mathrm{km}$ \\
\hline Short circuit resistance & $0.05 \Omega$ \\
\hline Active power load of each phase & $0.25 \mathrm{MW}$ \\
\hline Power factor of each phase & 0.97 inductive \\
\hline Phase-to-phase nominal voltage & $20 \mathrm{kV}$ \\
\hline $\begin{array}{l}\text { Virtual impedance of DGs before fault } \\
\left(Z_{D G i_{-} \text {virt1 }}, Z_{D G i \_v i r t 2}, Z_{D G i_{-} \text {virto }}\right)\end{array}$ & $(2 \mathrm{j}, 2 \mathrm{j}, 2 \mathrm{j}) \Omega$ \\
\hline $\begin{array}{l}\text { Virtual impedance of DGs during the fault } \\
\quad\left(Z_{D G i \_v i r t 1}, Z_{D G i \_v i r t 2}, Z_{D G i \_v i r t 0}\right)\end{array}$ & $\begin{array}{l}\text { Case } 1:(20 \mathrm{j}, 20 \mathrm{j}, 20 \mathrm{j}) \Omega \\
\text { Case } 2:(70 \mathrm{j}, 70 \mathrm{j}, 70 \mathrm{j}) \Omega\end{array}$ \\
\hline $\begin{array}{l}\text { Reference voltage of droop equation } \\
\qquad\left(V_{r e f(i)}\right)\end{array}$ & $11547 \mathrm{~V}$ \\
\hline $\begin{array}{l}\text { Reference frequency of droop equation } \\
\qquad\left(f_{\text {ref }(i)}\right)\end{array}$ & $50 \mathrm{~Hz}$ \\
\hline $\begin{array}{l}\text { Reactive power droop gain of DG } \\
\qquad\left(K_{Q(i)} \text { for } i=\{1,2,3\}\right)\end{array}$ & $10^{-4} \mathrm{~V} / \mathrm{Var}$ \\
\hline $\begin{array}{l}\text { Active power droop gain of DG } \\
\qquad\left(K_{P(i)} \text { for } i=\{1,2,3\}\right)\end{array}$ & $10^{-7}(\mathrm{~Hz} / \mathrm{W})$ \\
\hline
\end{tabular}




\section{Performance InVestigation}

\section{A) Network Description}

In order to test the performance of the proposed method, we applied it in a modified version of the IEEE 8500-node network [27]. The investigated network is a large islanded network, as shown in Fig. 7, at the end of the paper. It consists of 4 IBDGs operating in droop-control with VICLs. All the data of the network and DGs are provided in Table VII. IBDGs are assumed to generate balanced phase-to-neutral voltage $\left(Z_{D G i \_ \text {virt } 0}=Z_{D G i_{-} \text {virt } 2}=0\right)$ before and during the fault.

Due to the very large size of the network, a comparison against Simulink is not possible for this network. For this reason, we performed a comparison between the proposed and the analytical power flow (note that in the analytical power flow, the load buses are modeled with constant impedances). The fault currents of both methods are depicted in Table VIII, at the end of the paper, for two different fault locations (indicated in Fig. 7) and types of faults. As shown, the results of the proposed SCC method are very close with those of analytical power flow, confirming again the accuracy of our method, in a large islanded MG. It is worth noting that the slight differences between the two models arise from the different modelling of load buses (in the proposed method, loads have their pre-fault values, while in the analytical they are assumed constant impedances).

\section{B) Discussion about the results}

According to the results of Table VIII, the fault currents of DGs are significantly affected by the fault location. A raised question is what are the proper values of virtual impedances of DGs in order to fulfil two necessary requirements: a) effective current limitation of DGs for all possible fault locations, b) proper coordination with the protection devices. For instance, very large values of virtual impedances restrict, effectively, the current, for all possible fault locations, but may cause maloperation in the overcurrent protection devices, due to the very low values of fault current.

The proper selection of virtual impedances, during the fault, and the interaction they have with the protection devices, are only some of the issues that require further investigation. In any case, the proposed SCC algorithm can constitute an important tool for studying fault currents both in the planning stage as well as in the real-time applications of islanded MGs e.g circuit breaker/fuse breaking capability, relay coordination, earth fault currents calculation, fault location, isolation and supply restoration [2].

\section{C) Computation time}

The proposed approach converges after 20 iterations, while the total computation time is around $8 \mathrm{~ms}$. Given the large size of the network, we believe that this time is very low, confirming the ability of the proposed method to calculate efficiently, in real-time, the steady-state fault currents of large islanded droop-controlled MGs. The low computation time of the proposed method is explained by the fact that it considers into the calculation only the DG and faulted buses and not the load buses, which are by far the most numerous, reducing significantly the computation complexity. For comparison, in the analytical power flow (were all the buses are involved in the short-circuit analysis), the computation time would be around 4 seconds $(0.2 s$ per iteration x 20 iterations $)$. For the sake of fairness, all simulations were executed in a PC 64-bit Intel Core i7, 3.4GHz CPU with 16GB RAM.

TABLE VII

DATA OF THE 8500-NODE NETWORK

\begin{tabular}{|c|c|}
\hline Line Lengths & Given in [27] \\
\hline Resistance of the lines & Given in [27] \\
\hline Reactance of the lines & Given in [27] \\
\hline Short circuit resistance & $0.05 \Omega$ \\
\hline Active power load of each phase & Given in [27] \\
\hline Power factor of each phase & 0.97 inductive \\
\hline Phase-to-neutral nominal voltage & $7.2 \mathrm{kV}$ \\
\hline $\begin{array}{l}\text { Virtual impedance of DGs before fault } \\
\left(Z_{D G i \_v i r t 1}, Z_{D G i \_v i r t 2}, Z_{D G i \_v i r t 0}\right)\end{array}$ & $(0,0,0) \Omega$ \\
\hline $\begin{array}{l}\text { Virtual impedance of DGs during the fault } \\
\left(Z_{D G i \text { virt } 1}, Z_{D G i \_ \text {virt } 2}, Z_{D G i} \text { virt } 0\right)\end{array}$ & $(10 \mathrm{j}, 0 \mathrm{j}, 0 \mathrm{j}) \Omega$ \\
\hline $\begin{array}{l}\text { Reference voltage of droop equation } \\
\qquad\left(V_{r e f(i)}\right)\end{array}$ & $7.2 \mathrm{kV}$ \\
\hline $\begin{array}{l}\text { Reference frequency of droop equation } \\
\qquad\left(f_{\text {ref }(i)}\right)\end{array}$ & $50 \mathrm{~Hz}$ \\
\hline $\begin{array}{l}\text { Reactive power droop gain of DG } \\
\qquad\left(K_{Q(i)} \text { for } i=\{1,2,3\}\right)\end{array}$ & $2 \cdot 10^{-4} \mathrm{~V} / \mathrm{Var}$ \\
\hline $\begin{array}{l}\text { Active power droop gain of DG } \\
\quad\left(K_{P(i)} \text { for } i=\{1,2,3\}\right)\end{array}$ & $10^{-7}(\mathrm{~Hz} / \mathrm{W})$ \\
\hline
\end{tabular}

\section{CONCLUSION}

In this paper, a novel $\Delta$-circuit approach is proposed, which enables the fast calculation of fault currents in large islanded AC microgrids, supplied by grid-forming inverter-based distributed generators with virtual impedance current limiters. In contrast to the existing short circuit calculation methods that are only applicable in grid-connected networks, the proposed algorithm can be applied in islanded microgrids, considering accurately the current limiting strategies of inverter-based distributed generators. Moreover, the proposed method is characterized by very low computational complexity, which is a very important factor in real-time short-circuit analysis of a modern distribution management system. The proposed algorithm was validated against Simulink in a 9-bus and a 13bus network, while its computational performance is tested in a modified islanded version of IEEE 8500-node network.

\section{REFERENCES}

[1] R. A. Jabr and I. Dzafic, "A fortescue approach for real-time short circuit computation in multiphase distribution networks", IEEE Trans. Power Syst., vol. 30, no. 6, pp. 3276-3285, Nov. 2015.

[2] L. Strezoski, M. Prica and K. A. Loparo, "Generalized $\Delta$-circuit concept for integration of distributed generators in online short-circuit calculations," IEEE Trans. Power Syst., vol. 32, no. 4, pp. 3237-3245, Jul. 2017.

[3] J. Chen, H. Li, C. Deng and G. Wang, "Detection of Single-Phase to Ground Faults in Low-Resistance Grounded MV Systems", IEE Transaction on Power Delivery, pp. 1-10, 2020.

[4] V. Strezoski and D. Bekut, "A canonical model for the study of faults in power systems", IEEE Trans. Power Syst., vol. 6, no. 4, pp. 1493-1499, Nov. 1991.

[5] A. D. Paquette and D. M. Divan, "Virtual impedance current limiting for inverters in microgrids with synchronous generators", IEEE Trans. Ind. Appl., vol. 51, no. 2, pp. 1630-1638, Mar. 2015.

[6] M. Castilla, J. Miret, J. L. Sosa, J. Matas and L. G. Vicuna, "Grid-fault control scheme for three-phase photovoltaic inverters with adjustable 
power quality characteristics", IEEE Trans. Power Electron., vol. 25, no. 12, pp. 2930-2940, Dec. 2010.

[7] Q. Wang, N. Zhou and L. Ye, "Fault analysis for distribution networks with current-controlled three-phase inverter-interfaced distributed generators", IEEE Trans. Power Del., vol. 30, no. 3, pp. 1532-1542, Jun. 2015.

[8] W. Guo, L. Mu and X. Zhang, "Fault models of inverter-interfaced distributed generators within a low-voltage microgrid", IEEE Trans. Power Del., vol. 32, no. 1, pp. 453-461, Feb. 2017.

[9] A. Camacho, M. Castilla, J. Miret, A. Borell and L. G. Vicuna, "Active and reactive power strategies with peak current limitation for distributed generation inverters during unbalanced grid faults", IEEE Trans. Ind. Electron., vol. 62, no. 3, pp. 1515-1525, Mar. 2015.

[10] I. Sadehkhani, M. E. H. Golshan, J. M. Guerrero and A. Mehrizi-Sani, "A current limiting strategy to improve fault ride-through of inverter interfaced autonomous microgrids", IEEE Trans. Smart Grid, Vol. 8, No. 5, 2017.

[11] T. Qoria et. al, "Current limiting algorithms and transient stability analysis of grid-forming VSCs", Electric Power Systems Research Vol. $189,106726,2020$

[12] M. G. Taul, X. Wang, P. Davari and F. Blaabjerg, "Current limiting control with enhanced dynamics of grid-forming converters during fault conditions", IEEE J. Emerg. Sel. Topics Power Electron., Vol. 8, No. 2, 2020.

[13] X. Lu, J. Wang, J. M. Guerrero and D. Zhao, "Virtual impedance-based fault current limiters for inverter dominated AC microgrids", IEEE Trans. Smart Grid, Vo. 3, No. 3, 2018.

[14] D. Duckwitz et. al, "Experimental Short-Circuit Testing of GridForming Inverters in Microgrid and Interconnected Mode", NEIS 2018; Conference on Sustainable Energy Supply and Energy Storage Systems, 2018.

[15] S. F. Zarei, H. Mokhtari, M. A. Ghasemi and F. Blaabjerg, "Reinforcing fault ride through capability of grid forming voltage source converters using an enhanced voltage control scheme", IEEE Trans. Power Del., vol. 34 , no. 5 , pp. $1827-1842$, Oct. 2019.
[16] U. Maqbool and U. A. Khan, "Fault current analysis for grid-connected and Islanded microgrid modes", 2017 13th International Conference on Emerging Technologies (ICET), pp. 1-5, 2017.

[17] M. Brucoli et. al., "Fault behaviour in islanded microgrids", CIRED 2007, Session 4, Paper No. 0548, 2007.

[18] M. Khan et. al., "Evaluation of Fault Characteristic in Microgrids Dominated by Inverter-Based Distributed Generators with Different Control Strategies", IEEE 8th International Conference on Advanced Power System Automation and Protection (APAP), 2019.

[19] S. A. Gopalan et. al., "Fault analysis of an islanded multi-microgrid", 2012 IEEE Power and Energy Society General Meeting, 2012.

[20] T. Y. Hsieh et. Al., "Efficient network fault analysis method for unbalanced microgrid systems", Electric power and Energy Systems, Vol. 103, pp. 89-101, 2018

[21] N. Simic, L. Strezoski, B. Dumnic, "Short-Circuit Analysis of DERBased Microgrids in Connected and Islanded Modes of Operation", Energies, 14(19), 6372, 2021.

[22] Y. Ma et. Al. "Short-circuit calculation method for islanded micro-grid based on master-slave control", IEEE China International Conference on Electricity Distribution (CICED), 2016.

[23] Z. Wang et. Al., "The fault analysis method of islanded microgrid based on the U/f and PQ control strategy", International transactions on electrical energy systems, 2021.

[24] B. Dağ et. Al., "Static Modeling of Microgrids for Load Flow and Fault Analysis", IEEE Transactions on Power Systems, Vol. 32, Issue 3, pp. 1990 - 2000, 2017.

[25] E. E Pompodakis, G. Kryonidis, C. Demoulias, M. Alexiadis, "A Generic Power Flow Algorithm for Unbalanced Islanded Hybrid AC/DC Microgrids", IEEE Transactions on Power Systems, Vol. 36 , No.2, DOI: 10.1109/TPWRS.2020.3012815, March 2021.

[26] E.E Pompodakis, G.C Kryonidis, M. C Alexiadis, "A comprehensive load flow approach for grid-connected and islanded AC microgrids", IEEE Trans. Power Systems, vol. 35, no. 2, pp. 1143-1155, 2020.

[27] IEEE PES. (2021, October.) Distribution test feeders, "8500-Node Tes Feeder". [Online]. Available: http://www.ewh.ieee.org/soc/pes/dsacom/testfeeders/index.html

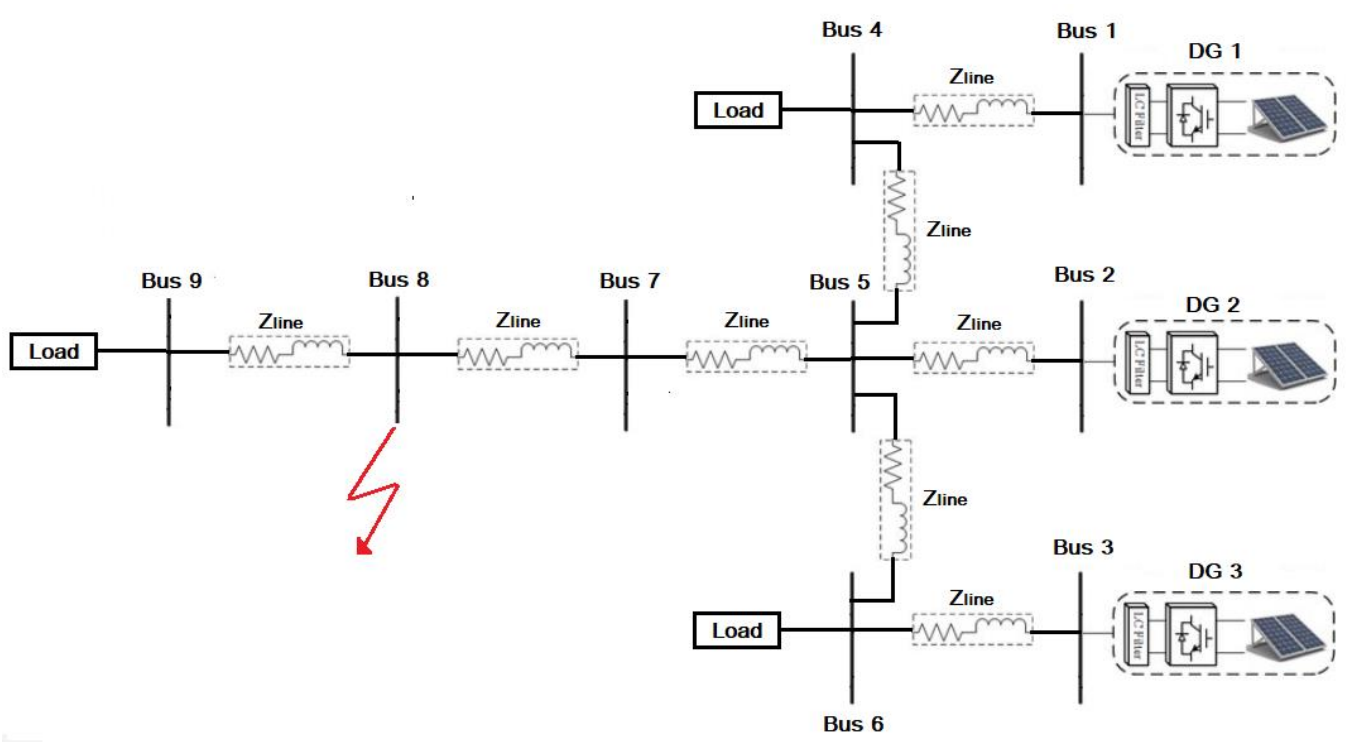

Fig. 5. 9-Bus islanded network consisting of 3 IBDGs with VICLs. 


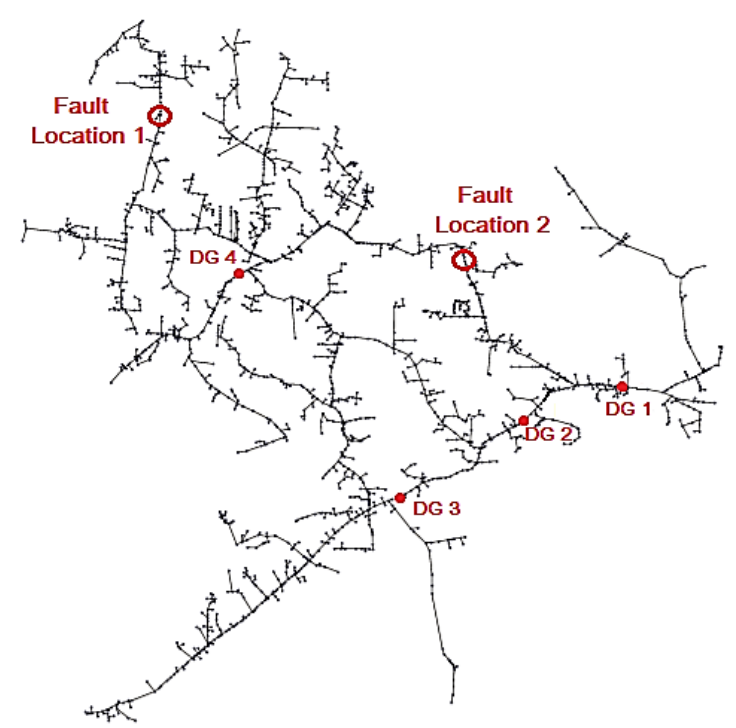

Fig.7. Modified islanded IEEE 8500-Node network with 4 IBDGs with VICLs. Two different fault locations are investigated.

TABLE II

Case 1 of 9-Bus Network: Fault Currents for Postfault Virtual Impedance Values of DGs equal to 20j

\begin{tabular}{|c|c|c|c|c|c|c|c|c|}
\hline Type of fault & \multicolumn{2}{|c|}{$\begin{array}{c}\text { Short circuit fault } \\
\text { at bus 8 }\end{array}$} & \multicolumn{2}{c|}{ Fault current of DG } & \multicolumn{2}{c|}{ Fault current of DG } & \multicolumn{2}{c|}{ Fault current of DG 3 } \\
& \multicolumn{2}{|c|}{ 1 } & \multicolumn{2}{c|}{$\mathbf{2}$} & \multicolumn{2}{l|}{} \\
\hline SLG & $\mathbf{9 8 0 . 5 1 6 1}$ & 994.6 & $\mathbf{3 3 1 . 6 2 7 3}$ & 329.2 & $\mathbf{3 5 5 . 0 6 9 7}$ & 353.5 & $\mathbf{3 3 1 . 6 2 7 3}$ & 329.2 \\
& $\mathbf{0 . 0 0 0 0}$ & 0 & $\mathbf{2 0 . 1 4 0 6}$ & 20.4 & $\mathbf{2 8 . 5 0 1 4}$ & 27.7 & $\mathbf{2 0 . 1 4 0 6}$ & 20.4 \\
& $\mathbf{0 . 0 0 0 0}$ & 0 & $\mathbf{2 2 . 6 7 4 4}$ & 22.1 & $\mathbf{2 2 . 2 8 8 3}$ & 21.5 & $\mathbf{2 2 . 6 7 4 4}$ & 22.1 \\
\hline LL & $\mathbf{9 3 1 . 6 7 1 6}$ & 945.0 & $\mathbf{3 2 3 . 1 6 8 1}$ & 320.9 & $\mathbf{3 4 6 . 9 6 2 7}$ & 344.9 & $\mathbf{3 2 3 . 1 6 8 1}$ & 320.9 \\
& $\mathbf{9 3 1 . 6 7 1 6}$ & 945.0 & $\mathbf{3 0 9 . 6 2 4 3}$ & 308.3 & $\mathbf{3 2 0 . 4 4 1 3}$ & 320.2 & $\mathbf{3 0 9 . 6 2 4 3}$ & 308.3 \\
& $\mathbf{0 . 0 0 0 0}$ & 0 & $\mathbf{1 8 . 8 8 9 8}$ & 18.0 & $\mathbf{3 0 . 2 7 8 7}$ & 28.5 & $\mathbf{1 8 . 8 8 9 8}$ & 18.0 \\
\hline 2LG & $\mathbf{9 8 3 . 6}$ & 1002.0 & $\mathbf{3 3 4 . 4 8 0 7}$ & 332.2 & $\mathbf{3 5 8 . 4 4 4 8}$ & 357.2 & $\mathbf{3 3 4 . 4 8 0 7}$ & 332.2 \\
& $\mathbf{1 0 4 5 . 8}$ & 1062.0 & $\mathbf{3 5 3 . 0 0 4 2}$ & 352.1 & $\mathbf{3 7 4 . 0 0 6 9}$ & 373.4 & $\mathbf{3 5 3 . 0 0 4 2}$ & 352.1 \\
& $\mathbf{0}$ & 0 & $\mathbf{1 8 . 5 6 1 2}$ & 18.3 & $\mathbf{3 2 . 6 5 4 8}$ & 31.1 & $\mathbf{1 8 . 5 6 1 2}$ & 18.3 \\
\hline 3LG & $\mathbf{1 0 2 9 . 5}$ & 1049.0 & $\mathbf{3 4 7 . 0 9 3 9}$ & 346.5 & $\mathbf{3 7 5 . 8 6 2 7}$ & 375.2 & $\mathbf{3 4 7 . 0 9 3 9}$ & 346.5 \\
& $\mathbf{1 0 2 9 . 5}$ & 1049.0 & $\mathbf{3 4 7 . 0 9 3 9}$ & 346.5 & $\mathbf{3 7 5 . 8 6 2 7}$ & 375.2 & $\mathbf{3 4 7 . 0 9 3 9}$ & 346.5 \\
& $\mathbf{1 0 2 9 . 5}$ & 1049.0 & $\mathbf{3 4 7 . 0 9 3 9}$ & 346.5 & $\mathbf{3 7 5 . 8 6 2 7}$ & 375.2 & $\mathbf{3 4 7 . 0 9 3 9}$ & 346.5 \\
\hline
\end{tabular}

*The results of the proposed method are with bold. The results of Simulink are with normal numbers. The units are in Ampere.

TABLE III

Case 2 of 9-Bus Network: Fault Currents for Postfault Virtual Impedance Values of DGs equal to 50j

\begin{tabular}{|c|c|c|c|c|c|c|c|c|}
\hline Type of fault & \multicolumn{3}{|c|}{$\begin{array}{c}\text { Short circuit fault at } \\
\text { bus 8 }\end{array}$} & \multicolumn{2}{|c|}{ Fault current of DG } & \multicolumn{2}{c|}{ Fault current of DG } & \multicolumn{2}{c|}{ Fault current of DG } \\
& \multicolumn{2}{|c|}{ 1 } & \multicolumn{2}{c|}{$\mathbf{2}$} & \multicolumn{2}{c|}{$\mathbf{3}$} \\
\hline SLG & $\mathbf{5 2 7 . 0 4 0 5}$ & 537.5 & $\mathbf{1 8 2 . 7 0 8 2}$ & 180.6 & $\mathbf{1 8 7 . 5 9 0 5}$ & 186.0 & $\mathbf{1 8 2 . 7 0 8 2}$ & 180.6 \\
& $\mathbf{0 . 0 0 0 0}$ & 0 & $\mathbf{2 1 . 5 2 2 1}$ & 21.1 & $\mathbf{2 4 . 6 0 0 9}$ & 23.6 & $\mathbf{2 1 . 5 2 2 1}$ & 21.1 \\
& $\mathbf{0 . 0 0 0 0}$ & 0 & $\mathbf{2 2 . 3 6 0 0}$ & 21.6 & $\mathbf{2 2 . 8 7 9 6}$ & 21.9 & $\mathbf{2 2 . 3 6 0 0}$ & 21.6 \\
\hline LL & $\mathbf{4 8 0 . 6 3 1 4}$ & 490.3 & $\mathbf{1 7 6 . 1 8 1 5}$ & 173.3 & $\mathbf{1 8 1 . 7 2 1 7}$ & 179.1 & $\mathbf{1 7 6 . 1 8 1 5}$ & 173.3 \\
& $\mathbf{4 8 0 . 6 3 1 4}$ & 490.3 & $\mathbf{1 5 7 . 4 7 0 9}$ & 156.4 & $\mathbf{1 5 8 . 4 9 3 2}$ & 158.1 & $\mathbf{1 5 7 . 4 7 0 9}$ & 156.4 \\
& $\mathbf{0 . 0 0 0 0}$ & 0 & $\mathbf{2 1 . 1 1 5 8}$ & 20.11 & $\mathbf{2 5 . 3 8 5 4}$ & 23.84 & $\mathbf{2 1 . 1 1 5 8}$ & 20.11 \\
\hline 2LG & $\mathbf{5 3 0 . 7 3 4 7}$ & 541.5 & $\mathbf{1 8 5 . 0 0 5 8}$ & 182.2 & $\mathbf{1 9 0 . 0 1 3 9}$ & 187.8 & $\mathbf{1 8 5 . 0 0 5 8}$ & 182.2 \\
& $\mathbf{5 4 0 . 7 1 4 8}$ & 552.2 & $\mathbf{1 8 6 . 4 5 5 2}$ & 184.8 & $\mathbf{1 9 0 . 9 2 6 5}$ & 189.7 & $\mathbf{1 8 6 . 4 5 5 2}$ & 184.8 \\
& $\mathbf{0 . 0 0 0 0}$ & 0 & $\mathbf{2 0 . 3 7 2 4}$ & 19.8 & $\mathbf{2 7 . 0 3 7 3}$ & 25.45 & $\mathbf{2 0 . 3 7 2 4}$ & 19.8 \\
\hline 3LG & $\mathbf{5 3 9 . 0 7 8 5}$ & 551.9 & $\mathbf{1 8 6 . 1 8 2 1}$ & 184.7 & $\mathbf{1 9 5 . 2 9 4 8}$ & 192.1 & $\mathbf{1 8 6 . 1 8 2 1}$ & 184.7 \\
& $\mathbf{5 3 9 . 0 7 8 5}$ & 551.9 & $\mathbf{1 8 6 . 1 8 2 1}$ & 184.7 & $\mathbf{1 9 5 . 2 9 4 8}$ & 192.1 & $\mathbf{1 8 6 . 1 8 2 1}$ & 184.7 \\
& $\mathbf{5 3 9 . 0 7 8 5}$ & 551.9 & $\mathbf{1 8 6 . 1 8 2 1}$ & 184.7 & $\mathbf{1 9 5 . 2 9 4 8}$ & 192.1 & $\mathbf{1 8 6 . 1 8 2 1}$ & 184.7 \\
\hline
\end{tabular}

*The results of the proposed method are with bold. The results of Simulink are with normal numbers. The units are in Ampere.

TABLE V

Case 1 of 13-Bus Network: Fault Currents for Postfault Virtual Impedance Values of DGs equal to 20j

\begin{tabular}{|c|c|c|c|c|c|c|c|c|c|c|}
\hline $\begin{array}{c}\text { Type of } \\
\text { fault }\end{array}$ & \multicolumn{2}{|c|}{$\begin{array}{c}\text { Short circuit } \\
\text { fault at bus 680 }\end{array}$} & \multicolumn{2}{|c|}{$\begin{array}{c}\text { Fault current of } \\
\text { DG 1 }\end{array}$} & \multicolumn{2}{c|}{$\begin{array}{c}\text { Fault current of } \\
\text { DG 2 }\end{array}$} & \multicolumn{2}{c|}{$\begin{array}{c}\text { Fault current of } \\
\text { DG 3 }\end{array}$} & \multicolumn{2}{c|}{$\begin{array}{c}\text { Fault current of } \\
\text { DG 4 }\end{array}$} \\
\hline SLG & $\mathbf{1 7 5 4 . 2}$ & 1781 & $\mathbf{4 4 3 . 7 5 6 6}$ & 438.8 & $\mathbf{4 4 3 . 8 2 1 5}$ & 438.8 & $\mathbf{4 6 8 . 6 2 1 6}$ & 464.3 & $\mathbf{4 6 7 . 8 8 6 3}$ & 464.3 \\
& $\mathbf{0 . 0 0 0 0}$ & 0 & $\mathbf{3 8 . 6 3 4 6}$ & 37.2 & $\mathbf{3 8 . 6 8 3 1}$ & 37.3 & $\mathbf{5 1 . 9 7 8 6}$ & 49.1 & $\mathbf{5 1 . 8 9 5 5}$ & 48.8 \\
& $\mathbf{0 . 0 0 0 0}$ & 0 & $\mathbf{4 3 . 7 5 7 2}$ & 41.6 & $\mathbf{4 3 . 8 0 1 7}$ & 41.6 & $\mathbf{4 6 . 4 3 2 6}$ & 43.8 & $\mathbf{4 6 . 3 0 8 8}$ & 43.5 \\
\hline
\end{tabular}




\begin{tabular}{|c|c|c|c|c|c|c|c|c|c|c|}
\hline LL & $\mathbf{1 5 7 2 . 6}$ & 1596 & $\mathbf{4 1 5 . 2 1 2 5}$ & 408.8 & $\mathbf{4 1 5 . 2 9 3 8}$ & 408.8 & $\mathbf{4 4 2 . 2 3 6 5}$ & 436.0 & $\mathbf{4 4 1 . 6 9 8 9}$ & 436.0 \\
& $\mathbf{1 5 7 2 . 6}$ & 1596 & $\mathbf{3 8 5 . 1 7 6 0}$ & 382.7 & $\mathbf{3 8 5 . 2 1 7 6}$ & 382.7 & $\mathbf{3 9 1 . 2 6 0 3}$ & 390.0 & $\mathbf{3 9 0 . 5 0 7 9}$ & 390.0 \\
& $\mathbf{0 . 0 0 0 0}$ & 0 & $\mathbf{3 5 . 4 2 1 7}$ & 32.7 & $\mathbf{3 5 . 4 9 3 8}$ & 32.7 & $\mathbf{5 4 . 9 7 6 5}$ & 50.7 & $\mathbf{5 4 . 9 1 3 9}$ & 50.4 \\
\hline 2LG & $\mathbf{1 7 2 3 . 0}$ & 1752 & $\mathbf{4 3 8 . 2 5 3 1}$ & 433.4 & $\mathbf{4 3 8 . 3 3 3 0}$ & 433.4 & $\mathbf{4 6 2 . 4 9 9 9}$ & 458.2 & $\mathbf{4 6 1 . 7 7 8 0}$ & 458.2 \\
& $\mathbf{1 7 5 2 . 4}$ & 1783 & $\mathbf{4 4 3 . 7 0 0 4}$ & 440.2 & $\mathbf{4 4 3 . 7 7 2 4}$ & 440.2 & $\mathbf{4 6 4 . 2 9 6 0}$ & 461.1 & $\mathbf{4 6 3 . 5 5 1 9}$ & 460.9 \\
& $\mathbf{0}$ & 0 & $\mathbf{3 1 . 1 2 6 8}$ & 29.93 & $\mathbf{3 1 . 2 3 4 2}$ & 30.0 & $\mathbf{6 0 . 9 9 6 9}$ & 56.16 & $\mathbf{6 1 . 0 4 4 4}$ & 55.67 \\
\hline 3LG & $\mathbf{1 6 6 3 . 3}$ & 1709 & $\mathbf{4 2 8 . 2 8 4 1}$ & 427.1 & $\mathbf{4 2 8 . 3 9 4 1}$ & 427.1 & $\mathbf{4 6 9 . 7 7 7 3}$ & 463.6 & $\mathbf{4 6 8 . 7 8 5 9}$ & 463.6 \\
& $\mathbf{1 6 6 3 . 3}$ & 1709 & $\mathbf{4 2 8 . 2 8 4 1}$ & 427.1 & $\mathbf{4 2 8 . 3 9 4 1}$ & 427.1 & $\mathbf{4 6 9 . 7 7 7 3}$ & 463.6 & $\mathbf{4 6 8 . 7 8 5 9}$ & 463.6 \\
& $\mathbf{1 6 6 3 . 3}$ & 1709 & $\mathbf{4 2 8 . 2 8 4 1}$ & 427.1 & $\mathbf{4 2 8 . 3 9 4 1}$ & 427.1 & $\mathbf{4 6 9 . 7 7 7 3}$ & 463.6 & $\mathbf{4 6 8 . 7 8 5 9}$ & 463.6 \\
\hline
\end{tabular}

*The results of the proposed method are with bold. The results of Simulink are with normal numbers. The units are in Ampere.

TABLE VI

Case 2 of 13-Bus Network: Fault Currents for Postfault Virtual Impedance Values of DGs equal to 70j

\begin{tabular}{|c|c|c|c|c|c|c|c|c|c|c|}
\hline $\begin{array}{c}\text { Type of } \\
\text { fault }\end{array}$ & \multicolumn{2}{|c|}{$\begin{array}{c}\text { Short circuit } \\
\text { fault at bus 680 }\end{array}$} & \multicolumn{2}{|c|}{$\begin{array}{c}\text { Fault current of } \\
\text { DG 1 }\end{array}$} & \multicolumn{2}{c|}{$\begin{array}{c}\text { Fault current of } \\
\text { DG 2 }\end{array}$} & \multicolumn{2}{c|}{$\begin{array}{c}\text { Fault current of } \\
\text { DG 3 }\end{array}$} & \multicolumn{2}{c|}{$\begin{array}{c}\text { Fault current of } \\
\text { DG 4 }\end{array}$} \\
\hline SLG & $\mathbf{5 8 8 . 3 0 4 6}$ & 602.1 & $\mathbf{1 5 4 . 0 0 0 2}$ & 152.0 & $\mathbf{1 5 4 . 0 2 0 9}$ & 152.0 & $\mathbf{1 5 6 . 1 7 5 6}$ & 154.5 & $\mathbf{1 5 5 . 9 3 4 8}$ & 154.4 \\
& $\mathbf{0 . 0 0 0 0}$ & 0 & $\mathbf{4 3 . 9 9 3 4}$ & 39.9 & $\mathbf{4 4 . 0 1 0 2}$ & 39.8 & $\mathbf{4 6 . 1 0 4 2}$ & 41.6 & $\mathbf{4 6 . 0 6 0 9}$ & 41.4 \\
& $\mathbf{0 . 0 0 0 0}$ & 0 & $\mathbf{4 4 . 6 7 4 8}$ & 40.5 & $\mathbf{4 4 . 6 9 1 6}$ & 40.4 & $\mathbf{4 5 . 4 2 2 3}$ & 41.0 & $\mathbf{4 5 . 3 7 8 8}$ & 40.8 \\
\hline LL & $\mathbf{5 1 5 . 4 5 3 0}$ & 528.5 & $\mathbf{1 5 5 . 8 9 0 1}$ & 152.1 & $\mathbf{1 5 5 . 9 1 8 8}$ & 152.1 & $\mathbf{1 5 8 . 5 8 7 1}$ & 154.0 & $\mathbf{1 5 8 . 3 9 6 1}$ & 153.9 \\
& $\mathbf{5 1 5 . 4 5 3 0}$ & 528.5 & $\mathbf{1 1 4 . 6 1 0 5}$ & 117.2 & $\mathbf{1 1 4 . 6 2 0 0}$ & 117.2 & $\mathbf{1 1 4 . 4 7 7 1}$ & 117.5 & $\mathbf{1 1 4 . 2 3 9 9}$ & 117.4 \\
& $\mathbf{0 . 0 0 0 0}$ & 0 & $\mathbf{4 3 . 6 1 5 0}$ & 39.1 & $\mathbf{4 3 . 6 4 1 9}$ & 39.1 & $\mathbf{4 6 . 4 6 9 4}$ & 41.65 & $\mathbf{4 6 . 4 4 2 0}$ & 41.48 \\
\hline 2LG & $\mathbf{5 8 5 . 3 4 8 2}$ & 598.7 & $\mathbf{1 5 4 . 0 1 0 8}$ & 151.5 & $\mathbf{1 5 4 . 0 3 4 1}$ & 151.4 & $\mathbf{1 5 5 . 8 2 8 6}$ & 153.6 & $\mathbf{1 5 5 . 5 9 0 0}$ & 153.6 \\
& $\mathbf{5 8 6 . 4 9 1 9}$ & 598.7 & $\mathbf{1 5 2 . 8 3 9 3}$ & 151.2 & $\mathbf{1 5 2 . 8 6 1 2}$ & 151.2 & $\mathbf{1 5 4 . 8 1 7 7}$ & 153.4 & $\mathbf{1 5 4 . 5 7 7 1}$ & 153.4 \\
& $\mathbf{0 . 0 0 0 0}$ & 0 & $\mathbf{4 2 . 3 8 7 1}$ & 38.5 & $\mathbf{4 2 . 4 3 1 9}$ & 38.3 & $\mathbf{4 7 . 6 9 4 9}$ & 42.4 & $\mathbf{4 7 . 6 9 7 1}$ & 42.2 \\
\hline 3LG & $\mathbf{6 0 5 . 6 6 9 9}$ & 594.4 & $\mathbf{1 4 7 . 6 5 8 3}$ & 150.2 & $\mathbf{1 4 7 . 6 2 4 7}$ & 150.2 & $\mathbf{1 5 1 . 3 2 3 6}$ & 153.4 & $\mathbf{1 5 1 . 5 7 8 8}$ & 153.4 \\
& $\mathbf{6 0 5 . 6 6 9 9}$ & 594.4 & $\mathbf{1 4 7 . 6 5 8 3}$ & 150.2 & $\mathbf{1 4 7 . 6 2 4 7}$ & 150.2 & $\mathbf{1 5 1 . 3 2 3 6}$ & 153.4 & $\mathbf{1 5 1 . 5 7 8 8}$ & 153.4 \\
& $\mathbf{6 0 5 . 6 6 9 9}$ & 594.4 & $\mathbf{1 4 7 . 6 5 8 3}$ & 150.2 & $\mathbf{1 4 7 . 6 2 4 7}$ & 150.2 & $\mathbf{1 5 1 . 3 2 3 6}$ & 153.4 & $\mathbf{1 5 1 . 5 7 8 8}$ & 153.4 \\
\hline
\end{tabular}

*The results of the proposed method are with bold. The results of Simulink are with normal numbers. The units are in Ampere.

TABLE VIII

8500-Node Network: Fault Currents for two different fault locations. Post-fault Virtual Impedance Values of DGs are

$\left(Z_{D G i \_ \text {virt } 1}, Z_{D G i_{\text {_virt } 2}}, Z_{\text {DGi_virt } 0}\right)=(10 \mathrm{j}, 0 \mathrm{j}, 0 \mathrm{j}) \Omega$

\begin{tabular}{|c|c|c|c|c|c|c|c|c|c|c|}
\hline \multirow{2}{*}{$\begin{array}{l}\text { Type } \\
\text { of } \\
\text { fault }\end{array}$} & \multicolumn{2}{|c|}{ Short circuit fault } & \multicolumn{2}{|c|}{$\begin{array}{l}\text { Fault current of DG } \\
1\end{array}$} & \multicolumn{2}{|c|}{$\begin{array}{l}\text { Fault current of DG } \\
\qquad 2\end{array}$} & \multicolumn{2}{|c|}{$\begin{array}{l}\text { Fault current of DG } \\
3\end{array}$} & \multicolumn{2}{|c|}{$\begin{array}{l}\text { Fault current of DG } \\
4\end{array}$} \\
\hline & Fault 1 & Fault 2 & Fault 1 & Fault 2 & Fault 1 & Fault 2 & Fault 1 & Fault 2 & Fault 1 & Fault 2 \\
\hline \multirow{6}{*}{ SLG } & 738.1620 & 1795.5 & 175.3812 & 569.4368 & 186.3292 & 624.6162 & 64.5793 & 131.5910 & 372.7232 & 466.0557 \\
\hline & 0 & 0 & 14.4536 & 52.1644 & 10.7004 & 87.3718 & 62.3058 & 129.4904 & 26.2323 & 29.0952 \\
\hline & 0 & 0 & 55.9077 & 71.4085 & 57.2811 & 94.0416 & 64.1701 & 134.1320 & 114.4627 & 105.4032 \\
\hline & 738.2762 & 1752.6 & 172.9925 & 567.0445 & 185.2135 & 621.9401 & 61.2757 & 129.3382 & 366.2320 & 461.7922 \\
\hline & 0.0000 & $\mathbf{0}$ & 15.0074 & 49.9032 & 9.9871 & 84.8945 & 62.4361 & 130.4416 & 27.3447 & 30.3276 \\
\hline & 0.0000 & $\mathbf{0}$ & 53.4384 & 67.4209 & 54.2036 & 90.7077 & 62.7745 & $\mathbf{1 3 2 . 6 3 7 7}$ & 111.3983 & $\mathbf{1 0 7 . 8 9 3 0}$ \\
\hline \multirow[t]{6}{*}{ LL } & 790.1418 & 1676.5 & 236.3474 & 584.1217 & 248.5169 & 627.3097 & 107.9311 & 208.7344 & 272.3978 & 320.2437 \\
\hline & 790.1418 & 1676.5 & 181.6344 & 507.9480 & 191.0820 & 548.4031 & 109.5052 & 212.0085 & 374.3946 & 458.5880 \\
\hline & 0 & 0 & 54.5488 & 120.5101 & 57.2403 & 172.0518 & 109.6756 & 214.5965 & 133.6417 & 139.8598 \\
\hline & 790.1053 & 1666.9 & 232.3363 & $\mathbf{5 7 7 . 4 0 3 3}$ & 244.9333 & 620.4136 & 104.9822 & 207.8225 & 266.3724 & 313.1460 \\
\hline & 790.1053 & 1666.9 & 180.0779 & 508.7196 & 190.1118 & 549.4366 & 106.3485 & 209.2911 & 372.9836 & 457.7757 \\
\hline & 0.0000 & $\mathbf{0}$ & 51.2578 & 114.0884 & 54.1715 & 166.6391 & 107.6787 & 213.2661 & 136.7600 & 143.3419 \\
\hline \multirow[t]{6}{*}{$2 \mathrm{LG}$} & 733.3436 & 1537.1 & 214.6117 & 503.8959 & 218.7271 & 522.8731 & 119.7733 & 227.5638 & 234.7398 & 319.6146 \\
\hline & 862.3461 & 1701.9 & 201.5045 & 499.8034 & 209.4612 & 529.1870 & 121.1674 & 228.9644 & 389.6083 & 464.0519 \\
\hline & 0 & 0.0000 & 58.4788 & 118.9644 & 56.7974 & 171.2249 & 120.6443 & 232.5357 & 153.7408 & 138.5958 \\
\hline & 734.0666 & 1529.1 & 210.1867 & 498.9703 & 214.8911 & $\mathbf{5 1 7 . 8 4 7 7}$ & 116.0614 & 225.5764 & 229.9161 & 316.1065 \\
\hline & 862.6986 & 1691.4 & 199.3754 & 499.4236 & 207.7794 & 528.9188 & 117.4560 & 227.0983 & 386.7396 & 461.9592 \\
\hline & 0 & 0 & 55.1269 & 111.4671 & $\mathbf{5 3 . 2 2 9 7}$ & 164.9618 & 119.0528 & 231.5077 & 157.0156 & 142.1840 \\
\hline \multirow[t]{6}{*}{$3 \mathrm{LG}$} & 751.0967 & 1272.7 & 201.6929 & 375.0812 & 190.2738 & 353.4218 & 167.0132 & 289.9670 & 256.5390 & 338.4254 \\
\hline & 764.5215 & 1303.6 & 207.2530 & 384.8972 & 206.3022 & 378.9957 & 168.4215 & 291.7800 & 250.9164 & 340.7395 \\
\hline & 788.7821 & 1342.9 & 215.5131 & 399.4872 & 215.6982 & 386.6409 & 171.3140 & 297.9794 & 249.0892 & 343.9249 \\
\hline & 752.3224 & 1266.2 & 197.5233 & 371.0464 & 186.8577 & 349.4464 & 163.2901 & 286.5512 & 253.6578 & 336.1712 \\
\hline & 765.8973 & 1297.5 & 203.4027 & 381.4645 & 202.4035 & 374.4896 & 164.8638 & 289.1212 & 248.8516 & 338.9111 \\
\hline & 789.2477 & 1334.9 & 211.6255 & 395.0145 & 211.3454 & 381.7211 & 167.5648 & 294.3652 & 246.4820 & 340.0174 \\
\hline
\end{tabular}

* The units are in Ampere. Values of proposed approach are with normal numbers. Values of analytical power flow are with bold numbers. 